METHODOLOGIC ISSUES

\title{
Effect of recall on estimation of non-fatal injury rates: a community based study in Tanzania
}

\author{
C Moshiro, I Heuch, A N Åstrøm, P Setel, G Kvåle
}

Injury Prevention 2005;11:48-52. doi: 10.1136/ip.2004.005645

See end of article for authors' affiliations

\section{Correspondence to:} Ms Candida Moshiro, Centre for International Health, University of Bergen, Armauer Hansen Building, N-5021 Bergen, Norway; candida. moshiro@student.vib.no

\begin{abstract}
Study objective: To investigate the effect of recall on estimation of non-fatal injury rates in Tanzania. Design: Retrospective population based survey.

Setting: Eight branches in an urban area and six villages in a relatively prosperous rural area in Tanzania. Subjects: Individuals of all ages living in households selected by cluster sampling.

Main outcome measures: Estimated non-fatal injury rates calculated at each of the 12 recall periods (one to 12 months before the interview).

Results: Out of a population of 15223 persons, 509 individuals reported 516 injuries during the preceding year. Of these $313(61.5 \%)$ were males and $196(38.5 \%)$ females. The data showed notable declining incidence rates from 72 per 1000 person-years when based on a one month recall period to 32.7 per 1000 person-years for a 12 month recall period (55\% decline). The decline was found for injuries resulting in fewer than 30 days of disability whereas rates for severe injuries (disability of 30 days or more) did not show a consistent variation with recall period. Decline in injury rates by recall period was higher in rural than in urban areas. Age, sex, and education did not notably affect recall.

Conclusions: Longer recall periods underestimate injury rates compared with shorter recall periods. For severe injuries, a recall period of up to 12 months does not affect the rate estimates. It is essential that a recall period of less than three months be used to calculate injury rates for less severe injuries.
\end{abstract}

n njuries are becoming a major cause of mortality and morbidity in less developed countries. The relative contribution of injuries to disability adjusted life years is expected to rise from $15 \%$ in 1990 to $20 \%$ in 2020 with the largest increase expected to occur in sub-Saharan Africa. Most studies on the incidence of injuries are based on health facility data. Self reported data obtained through community based surveys play an important part in the study of injury morbidity in less developed countries due to incompleteness and low utilisation of health facilities. ${ }^{2-4}$ However, one major limitation of such studies is recall bias.

A number of studies have investigated the effect of recall period on the estimates of injury rates for non-occupational ${ }^{5-9}$ and occupational injuries. ${ }^{10}{ }^{11}$ A study in the United States examined the effect of recall in estimating injury rates among children and adolescents with a reference period of 12 months. $^{6}$ The largest declines in injury rates were observed for the 0-4 year old children and for minor injuries. Similarly, Mock et al investigated the effect of recall bias on annual injury rates in a household survey in Ghana. ${ }^{7}$ They found a remarkable decline in injury rates from a one month recall to a 12 month recall, which was influenced by severity of injury but not by age, gender, and locality. A population based study in Brazil compared retrospective and prospective data collection methods among preschool children. Use of diaries prospectively resulted in five times as many injuries reported than the recall method, particularly for injuries not requiring medical care. ${ }^{9}$ In the United States, injury rates for farmers were compared using two months', 12 months', and 10 years' recall. The results showed that a recall period of more than two months was likely to underestimate injury rates. ${ }^{12}$ Most of the studies on effect of recall on injury rates have been conducted in developed countries. A review of literature produced only one study from sub-Saharan Africa on time effects in recall of injuries.

In this paper, we investigate the effect of recall on estimates of annual injury rates as an initial step in analysing data from a survey that measured injury morbidity in an urban and a rural location of Tanzania. The effects of recall are also examined for various subpopulations and by severity of injury.

\section{METHODS}

\section{Study site}

A community based survey was conducted within the Adult Morbidity and Mortality Project (AMMP) study areas in the United Republic of Tanzania. AMMP is a health and demographic surveillance system operating in six districts of Tanzania. Its aim is to measure rates and causes of morbidity and mortality. ${ }^{4}$ Since 1992, the areas are prospectively monitored through repeated censuses to ascertain the population at risk. Deaths are recorded through an active reporting system and cause of death is determined by verbal autopsy. ${ }^{413}$ The survey on injuries was conducted in Dar es Salaam city (an urban area) and Hai District (a rural area).

Dar es Salaam city lies on the east coast of Tanzania. The AMMP demographic surveillance population is situated in two of the three municipalities covering three areas: Ilala, Keko, and Mtoni. The three areas contain eight branches including approximately 63330 persons in 15269 households living in urban and periurban areas of the city. Hai District lies on the south western slopes of Mount Kilimanjaro in northern Tanzania. The AMMP demographic surveillance area in Hai covers 51 out of 61 villages in the district and around $62 \%$ of the total district population (159 906 persons in 40238 households). Agriculture, livestock keeping, and commercial mining are the main economic activities. Details of the study population have been described elsewhere. ${ }^{413} 14$

\section{Sampling procedure and participation rates Urban area}

A cluster sample of 2000 households was drawn from eight branches of the urban area. Information was sought on all 
individuals residing in the households. In total, 9200 individuals were eligible for study of whom 8188 (89.0\%) participated in the survey. The reasons for non-participation were: not found at home $191(2.1 \%)$, travelled $231(2.5 \%)$, moved $497(5.4 \%)$, house could not be traced $76(0.8 \%)$, and died $13(0.1 \%)$. Only four individuals refused to participate. No marked differences were found in demographic characteristics between those who participated and those who did not, except for slight differences in the age distribution in which participants were more likely to be aged between 5 and 14 years.

\section{Rural area}

A two stage cluster sampling method was adopted in selecting the study sample. In the first stage, six out of 51 villages were selected to represent different levels of socioeconomic status and injury mortality. Information on socioeconomic status and injury mortality for the villages was extracted from existing AMMP data. A random selection of 2000 households was drawn from all households of the selected villages in the second stage. The resulting sampling fraction was approximately the same for the six villages. All individuals in the selected households were included in the survey. In total, 7655 individuals constituted the sample. Of these, 7035 (91.9\%) participated in the survey. Reasons for non-response were: not found at home, 27 (0.4\%); moved, 119 (1.6\%); house could not be traced, six (0.1\%); died, 26 $(0.3 \%)$; and for $442(5.8 \%)$ individuals, their households were not covered. Comparison of demographic characteristics between respondents and non-respondents revealed no noticeable differences.

\section{Ethical clearance and informed consent}

Ethical clearance for this study was given by the Tanzania Commission for Science and Technology and the Regional Committee for Medical Research Ethics in Norway. During fieldwork, interviewers explained the aims of the study and sought informed verbal consent from each family to be included. For children below age 15, parents or guardians were interviewed; for adolescents aged 15-18, consent was obtained from both the parent and the child.

\section{Operational definitions \\ Injury}

An injury was included in this study if it had occurred in the past one year and resulted in losing one or more days of "normal" activity—for example, not being able to work or go to school.

\section{Severity of injury}

The number of days with restricted activity or disability days was considered as a measure of severity of injury. In this paper, we have used the groups $<30$ disability days and $\geqslant 30$ days to represent minor and severe injuries respectively.

\section{Data collection}

The survey tool was translated into Swahili (the local language), back translated into English, and pre-tested for comprehension before use in the field. Data collection took place from September to December 2002. Two questionnaires were used in the study. Questionnaire 1 recorded information on whether an individual had an injury during the past one year. A list of injuries (broken bones, cuts or sprains, burns, dental, or other injuries) or injury events (transport accidents, falls, sports activities, snake or other animal bite, electric current, near drowning, struck by object, attempted suicide, or other injuries) was read out to the respondents. The head of household was interviewed to elicit information about the household members. When the head of household was not available, the spouse or any other responsible person was taken as an interviewee.

Questionnaire 2 was used to record information concerning the description of the injury, the circumstances in which the injury occurred, and whether the injury was intended or not. Variables included were month and year, cause of the injury, place of occurrence, length of disability, and health facility use. Efforts were made to interview the injured person if an adult, otherwise we interviewed an informed member of the injured person's household.

\section{Data analysis}

Using the date in which the interview and injury took place, the time interval since the injury occurred was calculated in months. Since only the month and year were reported for the injury, the timing of the injury was assumed to be at the midpoint of the reported month. The calculated recall intervals range from one to 12 months. Injuries reported during the calendar month in which the interview took place were assigned an interval of 0 months. Assuming the interviews and injuries occurred at the midpoint of the month, then the intervals one to 12 cover an average period of one month whereas the interval 0 covers a period of two weeks. The intervals 0 and 1 were combined, resulting in a mean period of 1.5 months.

Going back in time, the estimated injury incidence rates were calculated for each recall month as the number of injuries reported for that recall period divided by the number of person-years. The person-years were calculated successively for more distant recall periods by multiplying the population at risk at each recall interval with a relevant proportion of a year. There were few individuals who had more than one injury episode in the preceding year. In such cases, only the most recent injury was included in the analysis.

Statistical analyses were performed using STATA (version 7. Stata Corporation, College Station, TX, USA). Incidence rates and their 95\% confidence intervals were calculated assuming a Poisson sampling distribution. To assess the change in incidence rates by recall period, we used a Poisson regression model. ${ }^{15}$ Since the relationship between recall period and the estimated incidence rates was not linear, recall period was included in the model as a categorical variable with four categories; first recall month, second recall month, from three to seven months' recall, and from eight to 12 months' recall. Interactions between the effect of recall period and demographic characteristics such as area, education, age, and sex were examined to determine whether change in injury rates with recall period varied between the subpopulations. A separate analysis was carried out taking into account the clustered nature of the data in the analysis. However, the standard errors did not change very much, so we report results that did not include adjustments for clustering.

\section{RESULTS}

A total of 509 injuries occurred to 15223 people during the year preceding the interview. Of these, $62 \%$ were to males, $40 \%$ to people from the urban area, and $64 \%$ were to individuals below 35 years of age.

Overall annual injury incidence was 72.0 per 1000 personyears for a one month recall period and 32.7 person-years using a one year recall period. Table 1 shows that for a one month recall period, the rates were significantly higher in the rural compared to urban area $(\mathrm{p}<0.001)$ and twice as high in males as in females $(p<0.001)$. The estimated rates were highest among those aged above 59 years and also highest among those who had primary education only. Figure 1 shows the overall estimated annual injury incidence rates by 
Table 1 Annual non-fatal injury rates per 1000 person-years at different recall periods by demographic characteristics

\begin{tabular}{|c|c|c|c|c|c|c|c|c|c|}
\hline \multirow[b]{2}{*}{ Variable } & \multirow[b]{2}{*}{ Population } & \multicolumn{2}{|c|}{1 month } & \multicolumn{2}{|c|}{2 months } & \multicolumn{2}{|c|}{ 3-7 months } & \multicolumn{2}{|c|}{ 8-12 months } \\
\hline & & No & Rate $(95 \% \mathrm{Cl})$ & No & Rate $(95 \% \mathrm{Cl})$ & No & Rate $(95 \% \mathrm{Cl})$ & No & Rate $(95 \% \mathrm{Cl})$ \\
\hline Total & 15223 & 137 & 72.0 (60.5 to 85.1$)$ & 58 & 46.1 (35.0 to 59.7) & 190 & 30.5 (26.3 to 35.2$)$ & 124 & 20.1 (16.7 to 23.9 ) \\
\hline $\begin{array}{l}\text { Setting } \\
\text { Dar es } \\
\text { Salaam }\end{array}$ & & & & & & & & & \\
\hline $\begin{array}{l}\text { (urban) } \\
\text { Hai (rural) }\end{array}$ & $\begin{array}{l}8188 \\
7035\end{array}$ & $\begin{array}{l}49 \\
88\end{array}$ & $\begin{array}{l}47.9(35.4 \text { to } 63.3) \\
100.1(80.3 \text { to } 123.3)\end{array}$ & $\begin{array}{l}17 \\
41\end{array}$ & $\begin{array}{l}25.1(14.6 \text { to } 40.1) \\
70.8(50.8 \text { to } 96.1)\end{array}$ & $\begin{array}{l}75 \\
115\end{array}$ & $\begin{array}{l}22.2(17.5 \text { to } 27.9) \\
40.3(33.3 \text { to } 48.4)\end{array}$ & $\begin{array}{l}65 \\
59\end{array}$ & $\begin{array}{l}19.4(15.0 \text { to } 24.8) \\
20.9(15.9 \text { to } 26.9)\end{array}$ \\
\hline \multicolumn{10}{|l|}{ Sex } \\
\hline Male & 7379 & 89 & 96.5 (77.5 to 118.8$)$ & 37 & 60.9 (42.9 to 83.9 ) & 106 & 35.3 (28.9 to 42.7$)$ & 81 & 27.3 (21.7 to 33.9 ) \\
\hline Female & 7844 & 48 & 48.9 (36.1 to 64.9$)$ & 21 & 32.3 (20.0 to 49.4$)$ & 84 & 26.1 (20.8 to 32.3$)$ & 43 & $13.4(9.7$ to 18.1$)$ \\
\hline \multicolumn{10}{|l|}{ Age (years) } \\
\hline $0-4$ & 1720 & 14 & 65.1 (35.6 to 109.3$)$ & 5 & 35.2 (11.4 to 82.1$)$ & 17 & 24.1 (14.0 to 38.6$)$ & 13 & 18.6 (9.9 to 31.8$)$ \\
\hline $5-14$ & 3711 & 33 & 71.2 (48.9 to 99.9 ) & 20 & 65.3 (39.9 to 100.8$)$ & 52 & $34.4(25.7$ to 45.1$)$ & 35 & 23.4 (16.3 to 32.5$)$ \\
\hline $15-59$ & 8627 & 78 & 71.8 (56.8 to 89.6$)$ & 31 & 43.5 (29.6 to 61.8$)$ & 101 & 28.6 (23.3 to 34.8$)$ & 67 & 19.2 (14.9 to 24.3 ) \\
\hline $60+$ & 1164 & 12 & 87.2 (45.1 to 152.3 ) & 2 & 20.8 (2.5 to 75.2 ) & 20 & 42.0 (25.7 to 64.9) & 9 & 19.2 (8.8 to 36.4 ) \\
\hline \multicolumn{10}{|l|}{ Education } \\
\hline None & 3546 & 27 & $60.9(40.2$ to 88.6$)$ & 9 & 30.7 (14.0 to 58.3$)$ & 35 & $24.0(16.8$ to 33.4$)$ & 26 & 18.0 (11.8 to 26.4$)$ \\
\hline Primary & 9674 & 100 & $82.7(67.3$ to 100.6$)$ & 43 & 53.9 (39.0 to 72.6$)$ & 136 & 34.5 (28.9 to 40.8$)$ & 83 & 21.3 (16.9 to 26.4$)$ \\
\hline Secondary+ & 2001 & 10 & $39.9(19.2$ to 73.5$)$ & 6 & 36.2 (13.3 to 78.7$)$ & 19 & 23.1 (13.9 to 36.0$)$ & 15 & $18.4(10.3$ to 30.3$)$ \\
\hline
\end{tabular}

recall period. The largest difference was observed between the first and second recall month, where it dropped from 72 per 1000 person-years to 46 per 1000 person-years respectively.

Injury rates decreased more rapidly with a longer recall period in the rural than in urban area $(p=0.01$; table 1$)$. In trying to explain the differences in recall patterns for the urban and rural area, we analysed the declines within the urban area by comparing the urban and periurban areas. The decline in injury rates for the urban and periurban areas was similar $(p=0.44)$. Injury rates were higher in males than in females across recall periods. However, the drop in injury rates with increasing recall period did not differ significantly in males and females $(p=0.25)$. Similar results were observed after adjusting for urban or rural residence.

Injury rates among different age groups varied across the four recall periods and they all tended to decrease with recall period (table 1). The tendency to decrease did not differ significantly between the age groups $(p=0.79)$, even after adjusting for urban or rural residence. Although the difference in reported injury rates in recall period l compared with period eight to 12 months was higher among those with primary education, the tendency of the rates to decrease was not significantly different between the education categories after allowing for locality $(\mathrm{p}=0.85)$.

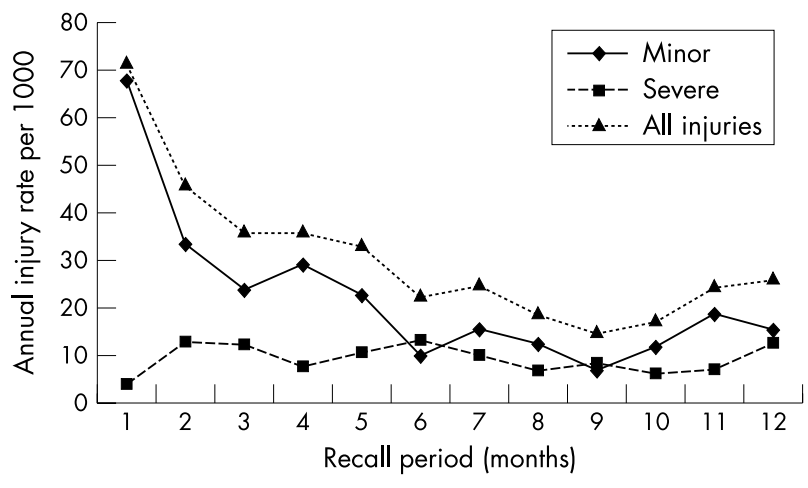

Figure 1 Overall annual injury rates per 1000 person-years by severity of injury and recall period $(n=15223)$.
Injury rates by recall period for minor and severe injuries are shown in fig 1 . The decline was seen to be stronger in minor injuries whereas for severe injuries there was no consistent pattern in injury rates for the different recall periods $(p<0.001$ for differences in rates of decline). For minor injuries resulting in fewer than 30 days of disability or restricted activity, the estimated annual injury rates declined by $81 \%$ from a one month to a eight to 12 month recall period. Variations in estimated rates by location for minor and severe injuries are indicated in table 2. The decline of minor injury rates from the one month to the eight to 12 month recall period was $84 \%$ and $75 \%$ for the rural and urban area respectively $(\mathrm{p}=0.21)$.

\section{DISCUSSION}

In this study, estimated annual injury rates varied with recall period, with shorter periods giving higher estimated rates than longer periods. This decline was observed for minor injuries only whereas no consistent decline was seen for severe injuries. This has great implications when estimating the magnitude of non-fatal injuries in a population.

Studies using interviewing techniques to ascertain injuries retrospectively through self or proxy report may be subject to recall bias. ${ }^{616}$ In surveys, there are two types of memory errors: loss of memory, that is failing to recall and therefore under-reporting events; and telescoping, the tendency to recall events as having occurred more recently than they actually did. ${ }^{6716}$ In our study, there was an increase in estimated rates in the 12th month of recall in comparison with the 10th or 11th month of recall. Possibly events that happened more than a year ago were being reported as occurring a year ago. However, the interviewers noted that the list of injuries and injury events was effective in aiding recall. Severe injuries will be under-represented in the first recall period, since reporting of injuries with disability duration of more than 30 days will be incomplete. This may explain the dip observed in the severe injury rate in the first recall period.

It is clear that sensitive events such as domestic violence, rape, or attempted suicide would be under-reported in such a study because of social stigma or fear of criminal implications. In many instances, an individual would be reporting for the other members of the household. There is a possibility 


\begin{tabular}{|c|c|c|c|c|c|}
\hline \multirow[b]{2}{*}{ Recall month } & \multirow[b]{2}{*}{ Person-years } & \multicolumn{2}{|c|}{ Minor injuries } & \multicolumn{2}{|c|}{ Severe injuries } \\
\hline & & No & Rate $(95 \% \mathrm{Cl})$ & No & Rate $(95 \% \mathrm{Cl})$ \\
\hline \multicolumn{6}{|c|}{ Dar es Salaam (urban) } \\
\hline 1 & 1023 & 46 & 44.9 (32.9 to 59.9$)$ & 3 & $2.9(0.6$ to 8.6$)$ \\
\hline 2 & 678 & 12 & 17.7 (9.1 to 30.9 & 5 & 7.4 (2.4 to 17.2 ) \\
\hline $3-7$ & 3371 & 44 & 13.1 (9.5 to 17.5$)$ & 31 & $9.2(6.2$ to 13.1$)$ \\
\hline $8-12$ & 3343 & 36 & 10.8 (7.5 to 14.9$)$ & 29 & 8.7 (5.8 to 12.5$)$ \\
\hline \multicolumn{6}{|l|}{ Hai (rural) } \\
\hline 1 & 879 & 84 & 95.6 (76.2 to 118.3) & 4 & 4.6 (1.2 to 11.7$)$ \\
\hline 2 & 579 & 30 & 51.8 (34.9 to 73.9$)$ & 11 & $18.9(9.5$ to 33.9$)$ \\
\hline $3-7$ & 2854 & 80 & $28.0(22.2$ to 34.9$)$ & 35 & $12.3(8.5$ to 17.1$)$ \\
\hline $8-12$ & 2821 & 40 & 14.2 (10.1 to 19.3$)$ & 19 & $6.7(4.1$ to 10.5$)$ \\
\hline
\end{tabular}

that the respondent would not be aware of all the injury incidents for the other members or would not report them accurately. In our study, information on type of respondent was not recorded from the whole study sample and therefore we could not assess the extent of memory decay by type of respondent.

Despite the limitations, our study still sheds some light on recall patterns of non-fatal injuries in a developing country. The overall estimated injury incidence was 72 and 32.7 per 1000 person-years for a one month and a 12 month recall period respectively, representing a decline of $55 \%$, with the largest decrease being between the first and second month. Our findings differ from those reported from Ghana, ${ }^{7}$ where the rate of decline was $72 \%$. However, it is not quite clear how the problem with injuries in the first recall month was handled in the study in Ghana. The 55\% decline from our study is slightly higher than the $40 \%$ decline reported from the United States. ${ }^{6}$ As Mock and colleagues indicated, ${ }^{7}$ it might be assumed that there was greater memory decay in the African data due to a lower level of formal education. However, we found a similar decline in estimated annual injury rates among those with and without formal education.

Comparisons with other studies are difficult due to differences in injury definition and classification of injury severity. The Tanzania Household Budget Survey of 2000/ 2001 conducted on a national representative sample of 22584 households recorded information on illness or injury in the four weeks before the interview. ${ }^{17}$ Among children aged less than 15 years and adults aged 15 years and above, $2.5 \%$ and $5 \%$ respectively reported to have been injured. This is quite high compared with our finding of about $1 \%$ in the above age groups. Although the former survey included all injuries irrespective of whether they were serious or not, our findings are probably an underestimate of the actual burden. In this study, the definition of injury did not refer to medical treatment since access to care is limited in developing countries. Comparison with other studies needs to be done with caution.

As expected, long recall periods were more likely to affect minor injuries than severe injuries. The most significant determinant of memory decay reported in other studies was the severity of the injury, ${ }^{5-8} 11$ although the various studies used different ways of classifying injury severity. From our study, the decline in estimated injury rates was significantly different for the rural and urban area, with those residing in the rural area having a greater tendency of memory decay. However, within the urban area, there were no differences in decline between the urban and periurban parts of the city. It is thus possible that basic cultural differences between population groups may account for the urban-rural contrast in memory decay. Although the decline in injury rates was

\section{Key points}

- Long recall periods were more likely to affect nonsevere injuries.

- Memory decay is not influenced by age, gender, and education.

- Recall of injury events is poor among people living in rural area.

- Short recall period is useful for estimating annual incidence rates for non-fatal injuries.

higher in the rural area for transport injuries and cuts, this did not explain the overall urban-rural differences. Our finding contrasts with results from Ghana where they found no difference in recall by urban-rural residence. ${ }^{7}$

We found a $57 \%$ decline in estimated rates for children aged $0-4$ years, with no notable differences in the decline of the rates in the other age groups. This is contrary to findings from other studies. In the American study, the decline in injury rates for children aged $<5$ years was $70 \%$ whereas for adolescents aged 14-17 years it was $41 \% .^{6}$ In Ghana, although memory decay was highest for children aged $<5$ years and aged 10-14 years (75\% decline), there were no marked differences between all age groups. ${ }^{7}$

Several studies have recommended using a one to three month recall period to minimise recall bias. ${ }^{6-8}$ However, such a short recall period requires having large sample sizes to ensure accurate estimates. In developing countries, surveys are useful for estimating both severe and non-severe injuries since health service data are usually incomplete. Although long recall periods underestimate injury rates especially for minor injuries, they can also be useful in investigating associations between injuries and different risk factors. ${ }^{10}$ For this particular purpose, it can be concluded that a one year recall period may be appropriate for assessing associations with both minor and severe injuries. However, for reliable estimation of the actual magnitude of non-fatal injury rates, a shorter recall period should be considered.

\section{ACKNOWLEDGEMENTS}

The first author is supported by the Norwegian State Educational Loan fund. This work was partly funded by the Norwegian Research Council. The efforts of our research assistants are acknowledged and appreciated. The study was done at Centre for International Health in University of Bergen in collaboration with the Adult Morbidity and Mortality Project (AMMP). AMMP is a project of the Tanzanian Ministry of Health, funded by the UK Department for International Development (DFID), and implemented in partnership with the 
University of Newcastle upon Tyne (UK). This publication is, in part, an output of AMMP; the views expressed are not necessarily those of DFID. David Whiting, Yusuf Hemed, Robert Mswia, and Gregory Kabadi were especially helpful in conducting the study in Tanzania. Finally, we thank all of the respondents from AMMP areas in Hai and Dar es Salaam, who have been participating in demographic surveillance since 1992.

\section{Authors' affiliations}

C Moshiro, A N Åstrøm, G Kvåle, Centre for International Health, University of Bergen, Norway

C Moshiro, Muhimbili University College of Health Sciences, Dar es Salaam, Tanzania

I Heuch, Department of Mathematics, University of Bergen, Norway P Setel, Adult Morbidity and Mortality Project, Tanzanian Ministry of Health and University of Newcastle upon Tyne, UK (at time of research); MEASURE Evaluation, Carolina Population Center, University of North Carolina at Chapel Hill (present)

\section{REFERENCES}

1 Murray CL, Lopez A. Alternative projections of mortality and disability by cause 1990-2020: Global Burden of Disease Study. Lancet 1997:349:1498-504.

2 Nordberg E. Injuries as a public health problem in sub-saharan Africa: epidemiology and prospects for control. East Afr Med J 2000;77:S1-43.

3 Mock CN, nii-Amon-Kotei D, Maier RV. Low utilization of formal medical services by injured persons in a developing nation: health service data underestimate the importance of trauma. J Trauma 1997;42:504-11.
4 Ministry of Health and AMMP Team. Policy implications of adult morbidity and mortality, End of phase 1 report. Dar es Salaam: United Republic of Tanzania, AMMP/Ministry of Health, 1997.

5 Silverbage CG. Validity of injury data collected by interview: a study of men born in 1913 and 1923. J Neurol Neurosurg Psychiatry 1983:46:818-23.

6 Harel Y, Overpeck MD, Jones DH, et al. The effects of recall on estimating annual nonfatal injury rates for children and adolescents. Am J Public Health 1994;84:599-605.

7 Mock C, Acheampong F, Adjei S, et al. The effect of recall on estimation of incidence rates for injury in Ghana. Int J Epidemiol 1999;28:750-5.

8 Langley JD, Cecchi JC, Williams SM. Recall of injury events by thirteen year olds. Methods Inf Med 1989;28:24-7

9 Fonseca SS, Victora CG, Halpern R, et al. Comparison of two methods for assessing injuries among preschool children. Inj Prev 2002;8:79-82.

10 Zwerling C, Sprince NL, Wallace RB, et al. Effect of recall period on the reporting of occupational injuries among older workers in the health and retirement study. Am J Ind Med 1995;28:583-90.

11 Landen DD, Hendricks S. Effect of recall on reporting of at-work injuries. Public Health Rep 1995; 110:350-4.

12 Jenkins P, Earle-Richardson G, Slingerland DT, et al. Time dependent memory decay. Am J Ind Med 2002;41:98-101.

13 Kitange H, Machibya H, Black J, et al. Outlook for survivors of childhood in sub-Saharan Africa: adult mortality in Tanzania. BMJ 1996:312:216-20.

14 Mswia R, Whiting D, Kabadi G, et al. INDEPTH DSS site profiles. In: INDEPTH Network, ed. Population and health in developing countries. Volume 1: population, health, and survival at INDEPTH sites. Ottawa: International Development Research Centre, 2002:143-50.

15 Kleinbaum DG, Kupper LL, Muller KE, et al. Applied regression analysis and other multivariable methods. 3rd Ed. Pacific Grove, CA: Duxbury Press, 1998:687-704

16 Coughlin SS. Recall bias in epidemiologic studies. J Clin Epidemiol 1990;43:87-91.

17 National Bureau of Statistics Tanzania. Household budget survey 2000/ 2001. Dar es Salaam: National Bureau of Statistics, 2002.

\section{BOARD MEMBER BIOGRAPHY}

\section{Jonathan Shepherd}

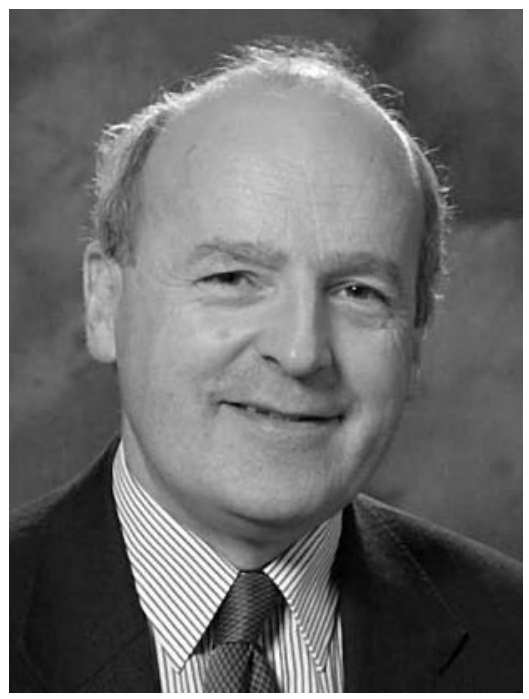

onathan Shepherd is Professor of Oral and Maxillofacial Surgery at the University of Cardiff, UK and Director of the Violence and Society Research Group there. His major clinical and research interest is trauma, particularly the surgery and epidemiology of violence. Among other research papers, his evaluations of urban CCTV and his randomised controlled trial of toughened glass have been published in Injury Prevention. He is the recipient of the Leibinger Prize of the International Association for Dental Research for his randomised experiments in alcohol misuse, and was the recipient of the 2003 Sellin and Glueck Award of the American Society of Criminology "for international contributions to criminology". He is qualified in public health and emergency medicine and is a Fellow of the Academy of Medical Sciences. 